\title{
Right Ventricular Myxoma- A Case Report
}

\author{
Ramachandran Muthiah \\ Thoothukudi Medical College Hospital, Thoothukudi, India \\ Email: cardioramachandran@yahoo.co.uk
}

Received 22 March 2016; accepted 23 April 2016; published 26 April 2016

Copyright (C 2016 by author and Scientific Research Publishing Inc.

This work is licensed under the Creative Commons Attribution International License (CC BY). http://creativecommons.org/licenses/by/4.0/

(c) () Open Access

\section{Abstract}

From an epidemiologic perspective, cardiac myxomas are best divided into the following 2 categories: those that arise in isolation and those that arise in the setting of a syndrome (so called Carney Complex). The former account for about $90 \%-95 \%$ of cases, while the later account for a minority of cases and those arise from the right or left ventricle constitute as $3 \%$ each. Real-time twodimensional echocardiography has proved to be extremely useful in defining intracavitary masses. With two-dimensional echocardiography accurate visualization of the right ventricular body and outflow tract can be accomplished consistently. The acoustic nature and anterior location of the right ventricular myxomas make them appear as bright, mobile masses. The mobile nature of the tumor can easily be appreciated and its point of attachment, or stalk can be visualized accurately. Background of this case illustrates the transthoracic 2D echocardiographic pattern of right ventricular myxoma and its attachment by a pedicle to the anterior papillary muscle, masquerading as ball-valve thrombus and cardiac "stone" in tilted parasternal long axis-3 chamber views in a 15-year-old girl. Mahaim criteria to distinguish myxoma from organizing thrombus had been highlighted.

\section{Keywords}

Myxoma, Right Ventricle, Echocardiography, Ball-Valve Thrombus, Cardiac "Stone"

\section{Introduction}

Primary cardiac masses are rare and usually benign [1]. Approximately 75\% of primary cardiac tumors are benign, and of those, myxoma is the commonest, constituting more than $50 \%$ of primary benign cardiac tumors. Those of ventricular origin are uncommon. The right ventricular myxomas are only found in $2 \%$ - $4 \%$ of cases $[2]$. 
Although numerous theories have been posited regarding the etiology of cardiac myxomas, the precise histogenesis of these tumors remains to be determined. For a time, cardiac myxomas were believed to arise from mural thrombi [3]. However, the difference between myxomas and thrombi is substantial. Furthermore, histologically myxomas do not organize into fibrous tissue or show stratification, a classic feature of mural thrombi. Cardiac myxomas also behave differently from thrombi in tissue culture studies [4]. The body of evidence in support of the neoplastic nature of the myxomas has lead to the consensus that cardiac myxomas are not of thrombotic origin and are, indeed, neoplastic [5].

Studies have described the relationship between angiogenesis and tumor growth [6]. Cardiac myxomas produce vascular endothelial growth factor, probably inducing angiogenesis for tumor growth. Neoangiogenesis is involved in the development of masses in the heart, benign or malignant. The myxomas are vascular tumors and may be neovascularized by a branch of a coronary artey [7].

A cardiac myxoma is a neoplasm of uncertain histogenesis that occurs only on the endocardial surface. It has been postulated that the cells from which the tumors originate are the so-called reserve totipotential subendocardial cells capable of forming vascular structures [8] that have endothelial and neural markers. Studies with neuroendocrine markers using immunohistochemical techniques suggest that endocardial sensory nerve tissue is the origin of myxoma. The existence of an aneuploid cell population in a tumor is generally considered evidence that the lesion is neoplastic [9]. The presence of aneuploidy, as well as the findings of chromosomal abnormalities in the case of myxomas, suggests a neoplastic origin for this type of tumor.

Myxomas are polypoid, round, or oval, and typically pedunculated but can also arise in a sessile fashion. They are gelatinous with a smooth, papillary or lobulated surface and usually are white, yellowish, or brown. Histologic studies are characterized by the presence of lepidic cells (myxoma cells) embedded in a vascular myxoidstroma [10]. These cells are polygonal to stellate in shape with scant eosinophilic cytoplasm. Architecturally, myxoma cells form rings, cords, and nests that are often closely associated with capillaries and can also exist singly as stellate cells in a myxoid stroma.

Myxomas frequently have adherent thrombi on their surface. Myxoma cells exhibit immunoreactivity to caIretinin (75\% - 100\%). Calretinin, in particular, has been proved quite useful in discriminating cardiac myxomas from mural thrombi and papillary fibroelastomas both of which lack immunoreactivity to this substance. Both the papillary excrescence and surface thrombi can be friable in nature and undergo embolization. One study suggests that the expression of the mucin gene MUC5AC within sporadic cardiac myxomas may correlate with a lower risk of embolization [11]. Grossly, two-thirds of myxomas are relatively compact and polypoid and unlikely to fragment spontaneously [12], while the other one-third are gelatinous and friable and, thus prone to fragment and embolize [13]. Secondary degenerative changes such as tumor necrosis were present in $8 \%$ of cases and calcification in 10\% - 20\%. Complete calcification of tumor may occur in rare cases [14]. Although the clinical course of cardiac myxoma is considered by most to be entirely benign, isolated cases of cardiac myxomas undergoing so-called malignant change have been reported [15] and documented the malignant potential of the myxomas with respect to local invasion of the vessel wall, recurrence, independent growth, distant metastasis and areas of hypercellularity. Reports typically cite areas of hypercellularity, necrosis, and atypia as a rationale for this designation. However, in many instances, a true malignant process and mitoses are typically absent. In addition, it is likely that many of these examples represent misdiagnosed myxoid sarcomas, a distinct and separate entity. To date, no study has been able to document consistent reproducible differences between sporadic and familial myxomas at the gross or microscopic level.

It is suggested that these neoplastic cells are of primitive multi-potential mesenchymal origin that persists as embryonic residues during septation of the heart and differentiate into endothelial cells, smooth muscle cells, angioblasts, cartilage cells, and myoblasts [16]. The cells of a cardiac myxoma are histologically and histogenetically different from the fusiform cells of soft tissue myxomas. Thus, myxomas are grouped under the category of benign tumors of pluripotent mesenchyme.

Mass forming reactive and pseudoneoplastic growths such as calcified amorphous tumor are often mistaken for calcified myxoma. Organization (proliferating fibroblasts, capillaries, and loose myxoid extracellular matrix) is conspicuously absent. Hemosiderin deposition and cholesterol clefts are rarely seen. Most cases show fresh thrombi on the surface - a potential source of emboli [17]. They are distinct from mural thrombi in that they lack significant fifroblast proliferation and organization and they can arise in any cardiac chamber.

An isolated right ventricular myxoma originating from anterior papillary muscle is uncommon and so this case had been reported. 


\section{Case Report}

A 15-year-old asymptomatic girl was referred for screening echocardiography as a routine medical check-up. Her pulse rate was $80 \mathrm{bpm}$ and blood pressure 110/80 mmHg. Physical examination revealed no abnormal findings and cardiac examination was clinically normal. Blood chemistry, X-ray chest and ECG were normal. Twodimensional echocardiography revealed a $23.3 \times 7.3 \mathrm{~mm}$ size myxoma originating from the anterior papillary muscle of the right ventricle with an attachment by a pedicle with the appearance of "cluster of grapes" as shown in Figures 1-4 and masquerading as ball-valve thrombus and cardiac "stone" as shown in Figure 5, Figure 6. Screening of family members revealed normal. She was advised periodic follow up.

\section{Discussion}

Cardiac tumors were first described in the $18^{\text {th }}$ centuary by Boneti, however, many believe the description by Albers in 1835 is the first authentic report. Cardiac tumors, whether primary or metastatic are rare [18]. Myxomas are usually seen in adults. They are rarely seen in children, accounting for only $9 \%-15 \%$ of all cardiac tumors from birth to adolescence. Right ventricular occurrences are rare and sporadic cases of right ventricular myxomas have been reported [19]. Czapek, in 1891, was among the first to provide a pathological description of a right ventricular myxoma [20]. 102 cases of myxomas originated from the right ventricle have been reported in

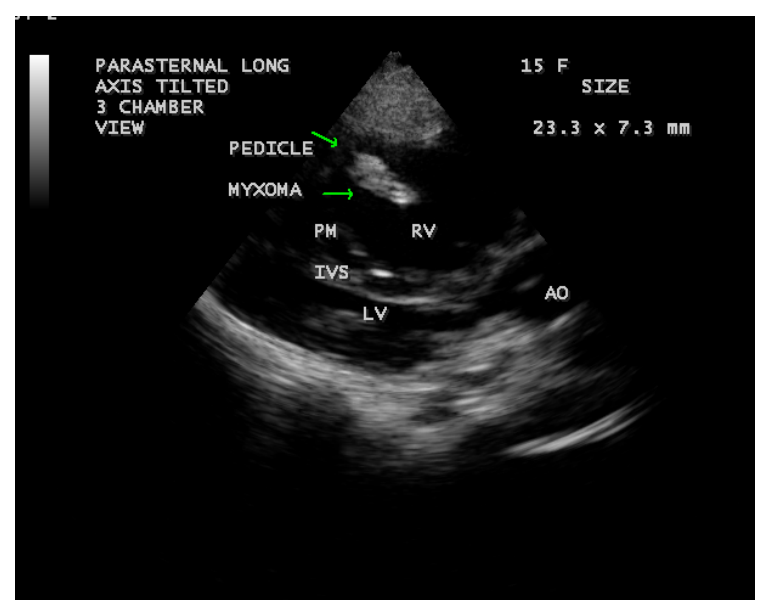

Figure 1. Tilted parasternal long axis-3 chamber view showing the myxoma near the right ventricular apex.

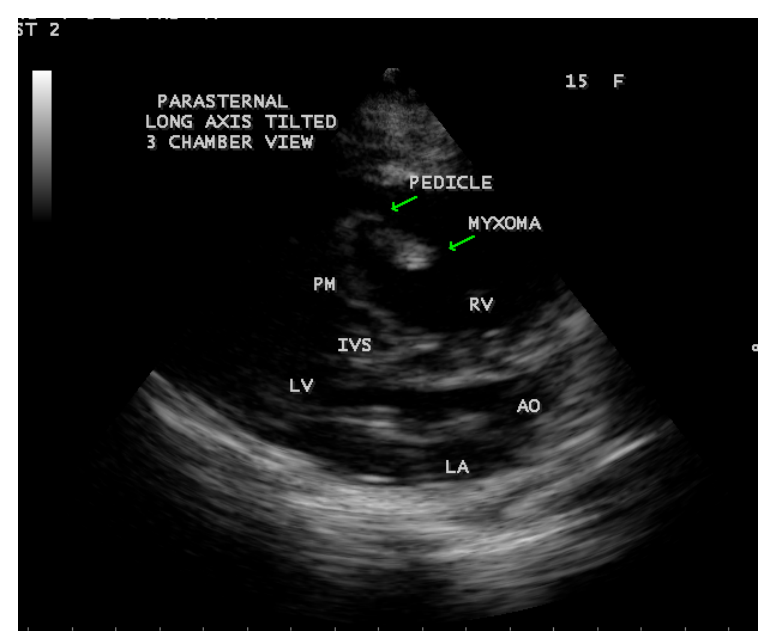

Figure 2. Tilted parasternal long axis-3 chamber view showing the myxoma attached by a pedicle to the papillary muscle. 


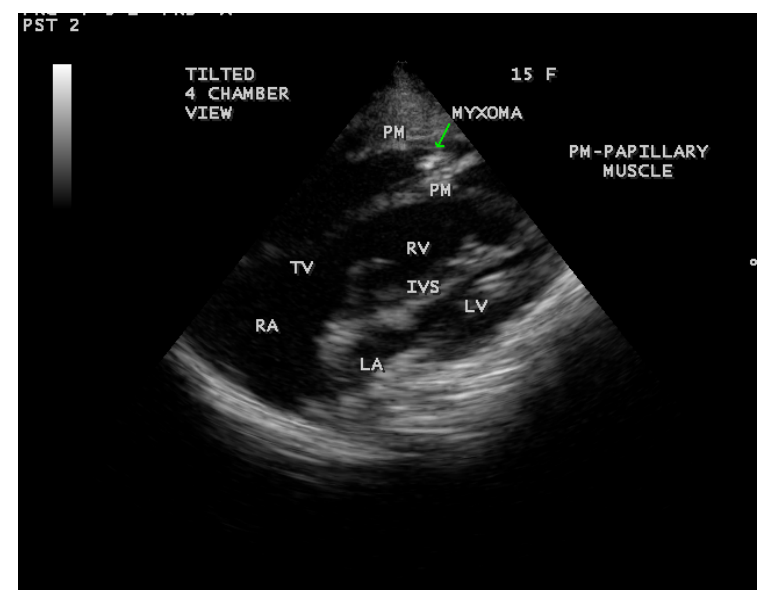

Figure 3. Tilted apical 4 chamber view showing the myxoma visible on the anterior papillary muscle.

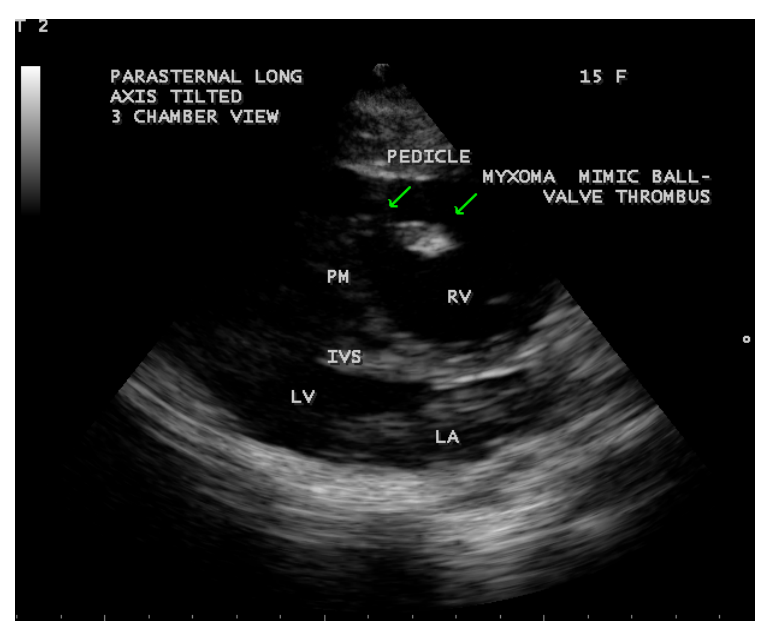

Figure 4. Tilted parasternal long axis-3 chamber view showing the myxoma masquerading as ball-valve thrombus with a bulbous end attached by a pedicle.

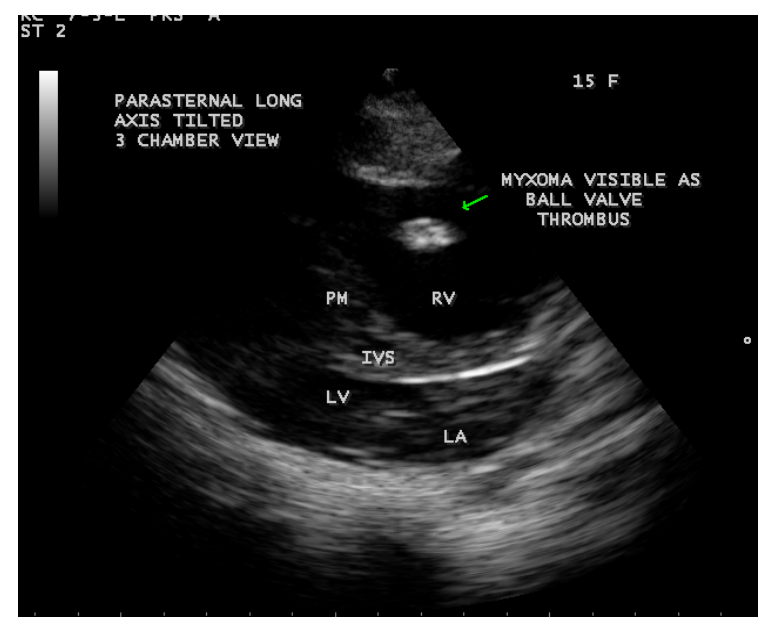

Figure 5. Tilted parasternal long axis-3 chamber view showing the myxoma masquerading as free-floating ballvalve, organized mural thrombus. 


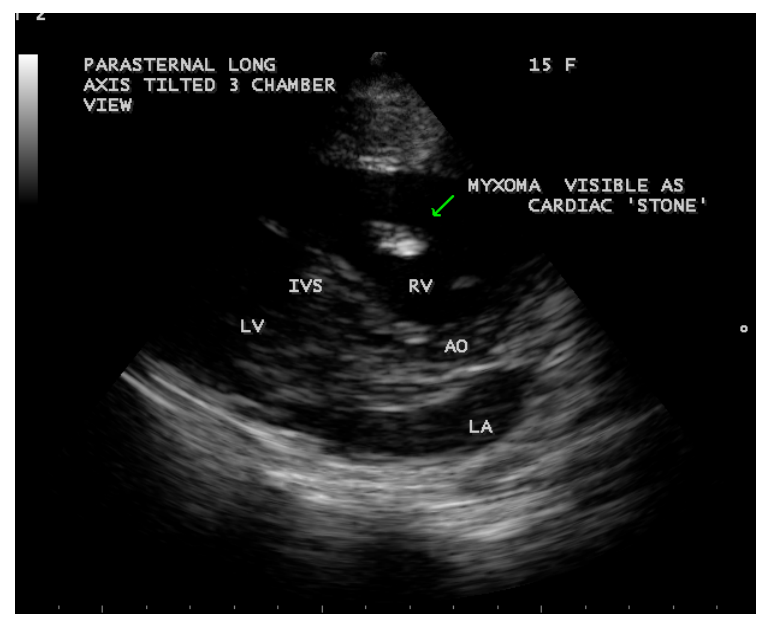

Figure 6. Tilted parasternal long axis -3 chamber view showing the myxoma masquerading as cardiac "stone".

the literature up to 2002. The sites of origin in the right ventricle are tricuspid valve, pulmonary valve, anterior papillary muscle, free wall and RV (Right Ventricular) apex. Free wall attachment is more commonly seen than other locations. The mean age of patients with myxomas located in the right or left ventricle was $18.50 \pm 6.36$ years.

\subsection{Echocardiography}

The frequency of cardiac tumor is low with an estimated cumulative prevalence of approximately $0.15 \%$ by echocardiographic evaluation [21]. Echocardiography is an excellent way to make a diagnosis by noninvasive means [22] [23]. Right ventricular myxomas may manifest as single or multiple intracardiac homogeneous, polypoid or papillary masses attached to the endocardium by a pedicle (stalk) or with a broad base. In this patient, Figure 1 revealed a pedunculated, polypoid mass near the right ventricular apex, and attached by a pedicle to the papillary muscle as in Figure 2 with a appearance of "cluster of grapes" and visible on the anterior papillary muscle as in Figure 3.

In 1923, Hustein stated the myxoma as myxomatous "polyps". They are thrombi in various stages of organization, which has little support now. It remains of prime importance, however, to consider the possibility of a mural thrombus masquerading as a pseudotumor whenever a polypoid tumor is observed attached to the endocardium. Criteria for distinguishing myxoma from organizing thrombi have been formulated by Mahaim [24] which was shown in the Table 1 given below.

Wood who first described the ball valve thrombus in year 1814 [25] and it is thought to be originating as a small mural thrombus. The thrombus gradually enlarges and form a projecting mass that remains attached by a pedicle. As the bulbous end of the thrombus enlarges, the pedicle lengthens and thin until eventually the thrombus separates or fragments. Thereafter as the thrombus spins freely, it acquires its characteristic smooth, polished appearance. In Figure 4, the myxoma mimicking as a ball-valve thrombus with a bulbous end attached by a pedicle.

Echocardiographic features of free-floating thrombus sometimes mimicked myxoma [26]. In myxomas, central areas of hyperlucency representing hemorrhage and necrosis, and the presence of calcification with echogenic foci can be detected by echocardiography. Following recurrent hemorrhage in the myxoma over time, impregnation of stromal connective tissue fibers with iron, calcium, and ceroid pigments may convert the myxoma into a sclerosiderotic nodule, termed as "Petrified cardiac myxoma" and masquerade as organized mural thrombi [27]. In Figure 5, the myxoma masquerade as free-floating ball valve, organized mural thrombus.

A calcified ball-valve thrombus sometimes mimic as a calcified myxoma. Calcification within a myxoma may follow tumor necrosis secondary to central infarction and repeated trauma and compression of the tumor once started, calcification may well encourage further necrosis by interfering with the blood supply of the myxoma and thereby cause the formation of a cardiac "stone" [28]. In Figure 6, the myxoma masquerade as a "cardiac stone”. 
Table 1. Mahaim criteria to distinguish myxoma from organizing thrombi.

\begin{tabular}{cc}
\hline Myxoma & Organizing thrombus \\
\hline $\begin{array}{c}\text { A pedunculated growth with a smooth } \\
\text { Glistening and transparent surface } \\
\text { Soft, gelatinous consistency }\end{array}$ & A stratified and friable surface \\
Absence of hemosiderin & Granular, opaque exterior \\
Mucin positive & Abundance of hemosiderin and fibrin \\
Covered with intact endocardium & Absence of mucin \\
Rooted into myocardium & A distinct demase with underlying \\
& endocardial lesion \\
& myocardium
\end{tabular}

\subsection{Future Perspective}

The exact etiology of myxomas was unknown. Analysis of the causes of myxoma is important to formulate therapy to inhibit its growth. Earlier studies state that mutation in the gene Protein Kinase A (PKA) had been identified in patients with both syndromic and non-syndromic cardiac atypical myxomas [29] (atypical myxoma means that the myxomas are not localizing in left atrium and interatrial septum). A recent study states that no germline mutations were detected in myxomas [30]. Some studies also describe the role of neoangiogenesis in the development of myxomas [31]. A recently published article identified the nutrient coronary vessel to right ventricular myxoma [32] and it is understanding a relationship between angiogenesis and tumor growth. This knowledge is important for the possible creation of adjuvant therapies for inhibition of the tumor in future.

\section{Conclusion}

An isolated right ventricular myxoma originating from the anterior papillary muscle was visualized by transthoracic two-dimensional echocardiography in a 15-year-old female child and masquerading as ball-valve thrombus and cardiac "stone" in tilted parasternal long axis-3 chamber views of echocardiographic imaging is an interesting feature. It is a rare incidence detected in Thoothukudi Region of Tamil Nadu State in India.

\section{References}

[1] Reynen, K. (1995) Cardiac Myxomas. New England Journal of Medicine, 333, 1610-1617. http://dx.doi.org/10.1056/NEJM199512143332407

[2] Crummy, A.B. and Hipona, F.A. (1964) The Radiographic Aspects of Right Ventricular Myxomas. British Journal of Radiology, 37, 468-471. http://dx.doi.org/10.1259/0007-1285-37-438-468

[3] Salyer, W.R., Page, D.L. and Hutchins, G.M. (1975) The Development of Cardiac Myxomas and Papillary Endocardial Lesions from Mural Thrombus. American Heart Journal, 89, 4-17. http://dx.doi.org/10.1016/0002-8703(75)90003-4

[4] Stratakis, C.A., Kirschner, L.S. and Carney, J.A. (2001) Clinical and Molecular Features of the Carney Complex: Diagnostic Criteria and Recommendations for Patient Evaluation. Journal of Clinical Endocrinology and Metabolism, 86, 4041-4046. http://dx.doi.org/10.1210/jcem.86.9.7903

[5] Leone, S., Dell’Acquila, G., Giglio, S., Magliocca, M., Maio, P., Nigro, F.S., et al. (2007) Infected Atrial Myxoma, Case Report and Literature Review. Le-Infezioni in Medicine, 15, 256-261.

[6] Kono, T., Koide, N., Hama, Y., et al. (2000) Expression of Vascular Endothelial Growth Factor and Angionesis in Cardiac Myxoma, a Study of Fifteen Patients. Journal of Thoracic Cardiovascular Surgery, 119, 101-107. http://dx.doi.org/10.1016/S0022-5223(00)70223-6

[7] Hasdemir, H., Alper, A.T., Arslan, Y. and Erdinler, I. (2011) Left Atrial Myxoma with Severe Neovascularization: Role of Preoperative Coronary Angiography. Turk Kardiyologi Dernegi Arsivi, 39, 163-165. http://dx.doi.org/10.5543/tkda.2011.01284

[8] Pucci, A., Gagliardotto, P., Zanini, C., Pansini, S., Di Summa, M. and Mollo, F. (2000) Histopathologic and Clinical Characterization of Cardiac Myxoma, Review of 53 Cases from a Single Institution. American Heart Journal, 140, 134-138. http://dx.doi.org/10.1067/mhj.2000.107176

[9] Barlogie, B. (1984) Abnormal Cellular DNA Content as a Marker of Neoplasia. European Journal of Cancer and 
Clinical Oncology, 20, 1123-1125. http://dx.doi.org/10.1016/0277-5379(84)90119-6

[10] Zheng, J.J., Geng, X.G., Wang, H.C., Yan, Y. and Wang, H.Y. (2013) Clinical and Histopathological Analysis of 66 Cases with Cardiac Myxoma. Asian Pacific Journal of Cancer Prevention, 14, 1743-1746. http://dx.doi.org/10.7314/APJCP.2013.14.3.1743

[11] Casey, M., Mah, C., Merliss, A.D., et al. (1998) Identification of a Novel Genetic Locus for Familial Cardiac Myxomas and Carney Complex. Circulation, 98, 2560-2566. http://dx.doi.org/10.1161/01.CIR.98.23.2560

[12] McAllister, H.A. and Fenoglio, J.J. (1978) Tumors of the Cardiovascular System. Atlas of Tumor Pathology, Series 2. Armed Forces Institute of Pathology, Washington DC, 2, 20.

[13] Pinede, L., Duhaut, P. and Loire, R. (2001) Clinical Presentation of Left Atrial Cardiac Myxomas: A Series of 112 Consecutive Cases. Medicine, 80, 159-172. http://dx.doi.org/10.1097/00005792-200105000-00002

[14] Lopez-Marco, A., Bin Esmael, T., Rowlands, G. and Von Oppell, U. (2014) Complete Calcification of Right Atrial Myxoma. European Journal of Cardiothoracic Surgery.

[15] Attum, A.A., Johnson, G.S., Masri, Z., Girardet, R. and Lansing, A.M. (1987) Malignant Clinical Behavior of Cardiac Myxomas and Myxoid “Imitators”. Annals of Thoracic Surgery, 44, 217-222. http://dx.doi.org/10.1016/S0003-4975(10)62052-8

[16] Lie, J.T. (1989) The Identity and Histogenesis of Cardiac Myxomas: A Controversy Put to Rest. Archives of Pathology and Laboratory Medicine, 113, 724-726.

[17] Reynolds, C., Tazelaar, H.D. and Edwards, W.D. (1997) Calcified Amorphous Tumor of the Heart (Cardiac CAT). Human Pathology, 28, 601-606. http://dx.doi.org/10.1016/S0046-8177(97)90083-6

[18] Tao, T.Y., Yahyavi-Firouz-Abadi, N., Singh, G.K. and Bhalla, S. (2014) Pediatric Cardiac Tumors; Clinical and Imaging Feature. Radiographics, 34, 1031-1046. http://dx.doi.org/10.1148/rg.344135163

[19] Gawdzinski, M.P. and Sypula, S. (1996) The Long Term Results of Treatment of Heart Myxomas with Special Attention to Very Rare Myxoma of the Right Ventricle. Journal of Cardiovascular Surgery, 37, 121-129.

[20] Melendez, L.J., Sears, G.A. and Coles, J.C. (1978) Right Ventricular Tumor Demonstrated by Echocardiography. Canadian Medical Association Journal, 118, 62-63.

[21] Urba, W. and Longo, D. (1986) Primary Solid Tumor of the Heart. In: Kapoor, A., Ed., Cancer of the Heart, Springer Verlag, New York, 62-75. http://dx.doi.org/10.1007/978-1-4612-4898-9_6

[22] Vander Heusen, F.J., Stratmann, G. and Russell, I.A. (2006) Right Ventricular Myxoma with Partial Right Ventricular Outflow Tract Obstruction. Anaesthesia and Analgesia, 103, 305-306. http://dx.doi.org/10.1213/01.ane.0000226144.27041.67

[23] Satitthummanid, S., Tumkosit, M., Benjacholamas, V., Chattranukulchai, P., Boonyaratavej, S. and Puwanant, S. (2011) Right Ventricular Myxoma. Journal of American College of Cardiology, 57, 630. http://dx.doi.org/10.1016/j.jacc.2010.04.076

[24] Fayen, A.W. and Baglio, C.M. (1959) Primary Myxoma Occurring in the Left Ventricle of the Heart. American Journal of Clinical Pathology, 32, 552-556. http://dx.doi.org/10.1093/ajcp/32.6.552

[25] Wrisley, D., Giambartolomerni, A. and Brownlee, W. (1991) Left Atrial Ball Valve Thrombus; Review of Clinical and Echocardiographic Manifestations with Suggestions for Management. American Heart Journal, 122, 1784-1790. http://dx.doi.org/10.1016/0002-8703(91)90027-F

[26] Shiu, M.F. and Abrams, L.D. (1983) Echocardiographic Features of Free Floating Thrombus Mimicking Right Ventricular Myxoma. British Heart Journal, 49, 612-614. http://dx.doi.org/10.1136/hrt.49.6.612

[27] Lie, J.T. (1989) Petrified Cardiac Myxoma Masquerading as Organized Atrial Mural Thrombus. Archives of Pathology and Laboratory Medicine, 113, 742-745.

[28] Stewart, J. and Saunders, N.R. (1982) Left Atrial Myxoma with Extensive Calcification. Thorax, 37, $224-225$. http://dx.doi.org/10.1136/thx.37.3.224

[29] Salpea, P. and Stratakis, C.A. (2014) Carney Complex and McCune Albright Syndrome. An Overview of Clinical Manifestations and Human Molecular Genetics. Molecular and Cellular Endocrinology, 386, 85-91.

[30] Massobria, L., Nastri, S., Martinuzzi, C., Chiarella, F., Montecucco, F., Rosa, G.M. and Valbusa, A. (2016) Mutation Analysis of PRKARIA Gene in a Patient with Atrial Myxoma. Journal of Clinical Laboratory Analysis, 30, 62.

[31] Rodriguez-Cruz, M.D.E. (2016) Pediatric Cardiac Tumors. Medscape Reference, Drugs, Diseases, and Procedures, 4 January 2016.

[32] Jiang, X., Wang, Y., Mohl, W. and Si, Z. (2015) Right Ventricular Myxoma Causing Right Ventricular Outflow Tract Obstruction-A Case Report. Open Journal of Clinical Diagnostics, 5, 121-124. http://dx.doi.org/10.4236/ojcd.2015.53020 